\title{
Microstructural and Chemical Rejuvenation of a Ni-Based Superalloy
}

\begin{abstract}
ZHIQI YAO, CRAIG C. DEGNAN, MARK A.E. JEPSON, and RACHEL C. THOMSON
The microstructural evolution of the Ni-based superalloy CMSX-4 including the change in gamma prime morphology, size, and distribution after high-temperature degradation and subsequent rejuvenation heat treatments has been examined using field emission gun scanning electron microscopy and transmission electron microscopy. In this paper, it is shown that there are significant differences in the size of the 'channels' between gamma prime particles, the degree of rafting, and the size of tertiary gamma prime particles in each of the different microstructural conditions studied. Chemical analysis has been carried out to compare rejuvenated and pre-service samples after the same subsequent degradation procedure. The results indicate that although the microstructures of pre-service and rejuvenated samples are similar, chemical differences are more pronounced in the rejuvenated samples, suggesting that chemical segregation from partitioning of the elements was not completely eliminated through the applied rejuvenation heat treatment. A number of modified rejuvenation heat treatment trials were carried out to reduce the chemical segregation prior to creep testing. The creep test results suggest that chemical segregation has an immeasurable influence on the short-term mechanical properties under the test conditions used here, indicating that further work is required to fully understand the suitability of specific rejuvenation heat treatments and their role in the extension of component life in power plant applications.
\end{abstract}

DOI: $10.1007 / \mathrm{s} 11661-016-3790-2$

(C) The Author(s) 2016. This article is published with open access at Springerlink.com

\section{INTRODUCTION}

NI-BASED superalloys are widely used in power generation for gas turbine components due to their excellent high-temperature performance. These components are subjected to an aggressive combination of elevated temperature and high stress during service, which causes significant microstructural degradation. $^{[1-4]}$ This microstructural deterioration includes coarsening of the strengthening $\mathrm{Ni}_{3} \mathrm{Al}$ precipitates $\left(\gamma^{\prime}\right)$ to form rafts and can also lead to local chemical segregation which can promote the formation of topologically close-packed phases (TCPs) and dendritic stress. ${ }^{[5-7]}$ This microstructural and chemical degradation deteriorates the mechanical properties of the material, which can reduce their service life and ultimately lead to component failure.

During a gas turbine engine's life, it undergoes a maintenance schedule that includes a periodic service and refurbishment procedure. Within this refurbishment procedure, microstructural rejuvenation of a blade may be carried out in an attempt to restore a partially

ZHIQI YAO, Research Student, MARK A.E. JEPSON, Lecturer in Metallurgy and Microscopy, and RACHEL C. THOMSON, Professor of Materials Engineering, are with the Department of Materials, Loughborough University, Loughborough, Leicestershire, LE11 3TU, U.K. Contact email: m.a.e.jepson@lboro.ac.uk CRAIG C. DEGNAN, Senior Materials Engineer, is with Uniper Technology Limited, Technology Centre, Ratcliffe-on-Soar, Nottingham, NG11 0EE, U.K.

Manuscript submitted May 8, 2016.

Article published online October 7, 2016 degraded microstructure to its pre-service condition through the application of specific heat treatments in an attempt to recover some additional service life from the component. In the case of the CMSX-4 alloy used for power plant applications, the predicted lifetime of the blade alloy is governed by chemical and mechanical degradation processes such as oxidation, thermal fatigue, and creep, but in some circumstances the degradation of the microstructure through the rafting of $\gamma^{\prime}$ particles must also be considered, especially when attempting to rejuvenate the microstructure.$^{\left[{ }^{[-1}[]\right.}$ Rafting is a process whereby, under the influence of stress and temperature, the optimum cube-shaped $\gamma^{\prime}$ particles elongate to form continuous rafts separated by widened Ni-matrix $(\gamma)$ channels. The direction of rafting depends on the direction of the applied stress with respect to the crystal direction within the material and on the sign of the $\gamma / \gamma^{\prime}$ lattice misfit. ${ }^{[12,13]}$ Generally, the direction of rafting is perpendicular to applied tensile stresses ${ }^{[13]}$ although this has been found to vary as a function of $\gamma^{\prime}$ content in the alloy. ${ }^{[14]}$ As rafting is a diffusion-based process, its rate is affected by the temperature of exposure and to the magnitude of stress applied. ${ }^{[15]}$ The strength of Ni-based superalloys is highly reliant on the size and distribution of $\gamma^{\prime}$ with fine and well-dispersed particles favorable for creep performance. Therefore, the formation of rafts is considered a softening process which deteriorates the high-temperature mechanical properties of the alloy due to the growth in width of the $\gamma$ matrix "channels" in between the $\gamma^{\prime}$ rafts. ${ }^{[8-11]}$ Therefore, understanding the changes in the 
size, morphology, and distribution of $\gamma^{\prime}$ particles during high-temperature degradation and rejuvenation heat treatments becomes very important. However, at present, limited information is available on the effect that these heat treatments have on the integrity of components.

In the absence of mechanical loads, the rafting behavior of $\gamma^{\prime}$ is associated with chemical gradients within the dendritic structure of the alloy. Hence, it is important to understand the effects of chemical segregation on the microstructure of the alloy and its mechanical behavior through, e.g., rafting characteristics. ${ }^{[16,17]}$ Rejuvenation heat treatments have been shown to reduce chemical segregation within components through the dissolution of $\gamma^{\prime}$, carbides, and TCP phases and subsequent re-precipitation of $\gamma^{\prime} \cdot{ }^{[18-20]}$ It is, therefore, essential to evaluate the influence of the rejuvenation heat treatments through the examination of the initial microstructure and subsequent microstructural degradation, chemical segregation, and mechanical performance after their application.

In this paper, the effects of a number of heat treatments applied to degraded CMSX-4 in an attempt to return the microstructure to the pre-service condition and to eliminate any chemical segregation are reported. Some short-term mechanical testing of the rejuvenated material has also been carried out in order to determine the role of chemical segregation in the performance of the rejuvenated material.

\section{EXPERIMENTAL PROCEDURE}

This investigation focused on the second-generation single-crystal Ni-based superalloy, CMSX-4, with the nominal chemical composition shown in Table I.

In order to produce creep test specimens, bar specimens measuring $20 \mathrm{~mm}$ in diameter and $\sim 150 \mathrm{~mm}$ in length were used. These were subsequently heat treated to the required condition (as described later). Creep tests were performed at a temperature of $1255 \mathrm{~K}\left(982{ }^{\circ} \mathrm{C}\right)$ and a stress of $167 \mathrm{MPa}$. These test conditions were designed to be similar but slightly more accelerated than creep tests performed by Svoboda and Lukas ${ }^{[21]}$ in which a pre-service virgin sample failed after $\sim 1500$ hours at a temperature of $1273 \mathrm{~K}\left(1000{ }^{\circ} \mathrm{C}\right)$ and a stress of $150 \mathrm{MPa}$. The single-crystal CMSX-4 creep test specimens were in the form of bars measuring $25 \mathrm{~mm}$ in length between the 'pips' with each head measuring $12 \mathrm{~mm}$ in diameter and a gauge length diameter of $6 \mathrm{~mm}$, as shown in Figure 1.

The heat treatments applied to the samples are detailed in Tables II and III. Pre-service samples underwent a "rafting" heat treatment (held at $1323 \mathrm{~K}$ $\left(1050{ }^{\circ} \mathrm{C}\right)$ for 1000 hours), to simulate microstructural degradation due to in-service thermal exposure only, then rejuvenated using a number of different heat treatments (Table III). These rejuvenated samples were subsequently re-rafted (i.e., by undergoing a further, identical "rafting" treatment) to simulate a further period in service. Four rejuvenation heat treatments were applied to enable systematic analysis of the microstructure of CMSX-4 to compare the different heat treatments (Table III). All of the heat treatments consisted of a solution heat treatment, to dissolve all $\gamma^{\prime}$, followed by an aging heat treatment. All of the solution heat treatments were based upon rejuvenation 1 (R1), a high-temperature rejuvenation heat treatment previously reported as a successful refurbishment treatment. ${ }^{[22]} \mathrm{A}$ number of modified rejuvenation heat treatments have been applied (R2, R3, and R4), which extend the length of the solution stage of the heat treatment procedure of $\mathrm{R} 1$. These were designed to establish the influence of the length of the rejuvenation heat treatment on the microstructural, chemical, and mechanical behavior of the material. After the solution heat treatments were complete, all the samples underwent the same initial aging heat treatment. Details of the precise rejuvenation treatment temperatures and hold times used are proprietary.

The applied modified rejuvenation heat treatments were applied as follows:

- (R2) Double the holding time for each stage of the high-temperature solution heat treatment to increase the time available for homogenization of the microstructure and chemical distribution.

- (R3) Five complete rejuvenation cycles where the solution heat treatment cycle was repeated in its entirety five times.

- (R4) Extended final step of the solution heat treatment procedure, where, instead of holding for 2 hours, the sample was held at the final high temperature for 60 hours.

For metallographic examination, specimens were cut and mounted in electrically conductive Bakelite, mechanically polished to a $1-\mu \mathrm{m}$ finish and then electrolytically etched at room temperature using 10 pct orthophosphoric acid in water at a voltage of

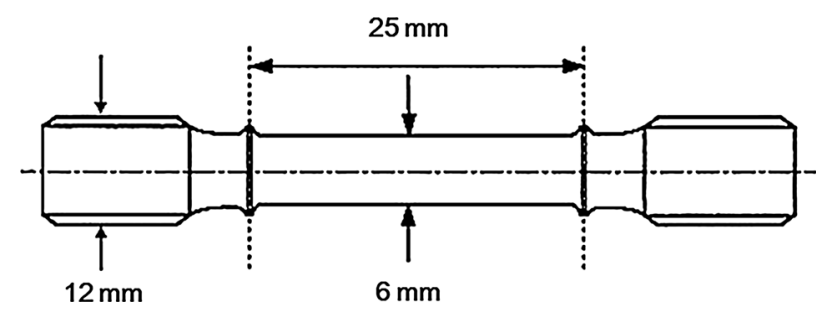

Fig. 1-Schematic diagram illustrating the details of the CMSX-4 creep specimen used in the project.

Table I. Nominal Chemical Composition of CMSX-4 Used in this Study (Weight Percent)

\begin{tabular}{lccccccccccccc}
\hline $\mathrm{Al}$ & $\mathrm{C}$ & $\mathrm{Co}$ & $\mathrm{Cr}$ & $\mathrm{Fe}$ & $\mathrm{Mo}$ & $\mathrm{Nb}$ & $\mathrm{Re}$ & $\mathrm{Hf}$ & $\mathrm{Ta}$ & $\mathrm{Ti}$ & $\mathrm{W}$ & $\mathrm{Ni}$ \\
\hline 5.70 & 0.0022 & 9.60 & 6.28 & 0.06 & 0.60 & 0.01 & 2.95 & 0.09 & 6.49 & 1.00 & 6.43 & balance \\
\hline
\end{tabular}


Table II. The CMSX-4 Samples with Their Heat Treatment Conditions

\begin{tabular}{lc}
\hline Sample & Heat Treatments \\
\hline S 1 & pre-service \\
S 2 & rafted \\
S $3(x)$ & $\begin{array}{c}\text { rafted }+ \text { rejuvenation } x \text { (where } x \text { indicates the rejuvenation } \\
\text { treatment applied from Table III) } \\
\text { rafted }+ \text { rejuvenation } x \text { (where } x \text { indicates the rejuvenation } \\
\text { treatment applied from Table III) }+ \text { Rafted }\end{array}$ \\
\hline
\end{tabular}

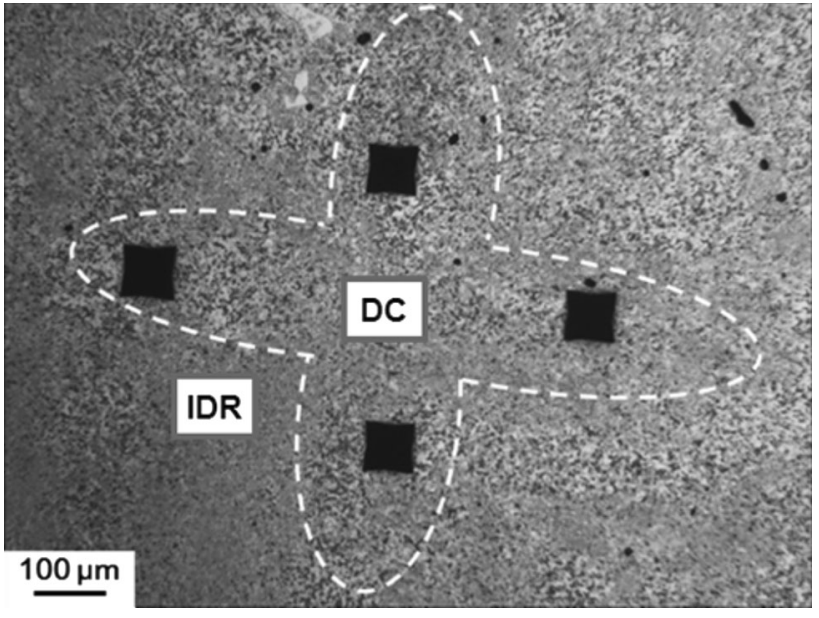

Fig. 2-Schematic illustration of the location of energy-dispersive X-ray spectroscopy (EDS) area analysis in the dendritic core (DC) and interdendritic region (IDR) with respect to the dendrite structure.

$10 \mathrm{~V}$. The majority of the microstructural examination was then carried out using a Leo 1530VP field emission gun scanning electron microscope (FEGSEM) and an FEI Tecnai field emission gun scanning transmission electron microscope (FEGSTEM). For chemical segregation analysis, the chemical composition difference between dendrite cores and interdendritic regions of all heat-treated samples was obtained using quantitative energy-dispersive X-ray spectroscopy (EDS) area analysis using an Oxford Instruments X-max 80 Silicon Drift Detector attached to the FEGSEM.

The dendrite structures were identified from the etched samples and their locations marked using hardness indents. In order to avoid the influence of etching on the chemical analysis, the etched surface was subsequently removed by polishing, leaving the diamond indents still visible on the sample's surface. An area measuring $20 \mu \mathrm{m} \times 20 \mu \mathrm{m}$ was analyzed both within the dendrite core areas and the interdendritic regions, as shown in Figure 2. The chemical composition difference between the dendrite cores and interdendritic regions was used to represent the chemical segregation within the samples. Where dendritic structures were not visible, chemical homogeneity was calculated by collecting EDS data from 20, $20 \mu \mathrm{m} \times 20 \mu \mathrm{m}$ randomly located areas and determining the difference between the highest and lowest elemental composition values, which therefore gives an indication of homogeneity within the sample whether relating to the location of dendrites or not.

When considering the rafting of these alloys, it is necessary to note that the rafting heat treatment was carried out in the absence of an applied external load. Therefore, although the heat treatment is designed to cause microstructural degradation analogous to in-service rafting, the direction of the rafting degradation may be affected by the presence of any internal stresses. Therefore, in this study, the rafting direction is defined as the direction along which the rafts have preferentially grown in each sample rather than the direction relative to an applied load.

In order to define the degree of rafting, a rafting parameter, $R$, defined by Ignat et al. ${ }^{[23]}$ as

$$
R=\frac{2 L^{2}}{4 L T}=\frac{L}{2 T}
$$

was used, where $L$ is the average length of the $\gamma^{\prime}$ rafts and $T$ is the average thickness of the $\gamma^{\prime}$ rafts. Using this formula, a cuboidal $\gamma^{\prime}$ particle would have a rafting parameter of 0.5 based on a 2-dimensional cross section. However, the process of rafting results in very large $L$ and relatively small $T$ values, which in turn leads to greater values of $R$.

Creep tests were carried out using static weight creep machines in accordance with ASTM E139 ${ }^{[24]}$ at two stress levels, one to correspond to the results from Reference 21 and the other to give a longer duration of test. The short-term tests were carried out at a stress of $425 \mathrm{MPa}$ and a temperature of $1173 \mathrm{~K}\left(900^{\circ} \mathrm{C}\right)$, and the longer-term tests were carried out at a stress of $167 \mathrm{MPa}$ and a temperature of $1255 \mathrm{~K}\left(982^{\circ} \mathrm{C}\right)$.

\section{RESULTS AND DISCUSSION}

\section{A. Microstructural Examination and Quantification}

Figure 3 shows the microstructure of the CMSX-4 samples in the pre-service $(\mathrm{S} 1)$, rafted $(\mathrm{S} 2)$, rejuvenated (S3(1)), and re-rafted (S4(1)) conditions. The microstructures of the pre-service and rejuvenated samples were very similar; both exhibited a uniform distribution of the secondary (cuboidal) $\gamma^{\prime}$, with a size of $\sim 0.5$ to $1 \mu \mathrm{m}$. S2 and $\mathrm{S} 4(1)$ had a degraded microstructure with larger and elongated $\gamma^{\prime}$ particles, the size of which ranges from a few micrometers to $20 \mu \mathrm{m}$. The rafts in S4(1) were much longer and more orientated than those in S2. The high-magnification 

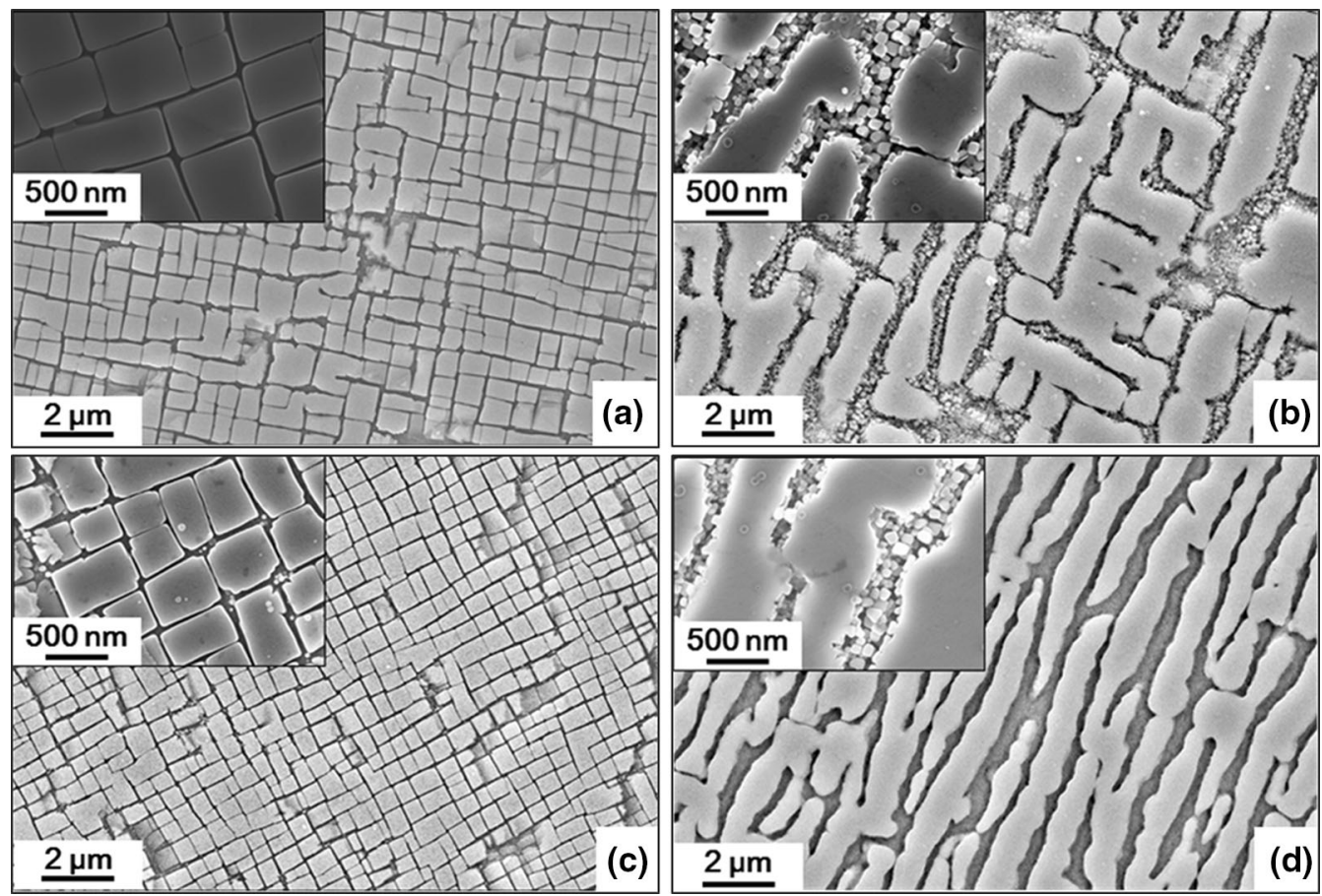

Fig. 3-SEM images of the CMSX-4 samples after four different heat treatment conditions: $(a)$ S1, as-received, (b) S2, rafted, (c) S3(1), rafted + $\mathrm{R} 1$, and $(d) \mathrm{S} 4(1)$, rafted $+\mathrm{R} 1+$ rafted.

Table III. Details of Heat Treatments Applied to CMSX-4 Samples

\begin{tabular}{lcccc}
\hline & & Solution heat treatment & & \\
\cline { 2 - 5 } Rafting & $\mathrm{R} 1$ & $\mathrm{R} 2$ & $\mathrm{R} 3$ & $\mathrm{R}$ \\
\hline $\begin{array}{l}\text { Holding at } 1323 \mathrm{~K} \\
\left(1050^{\circ} \mathrm{C}\right) \text { for } 1000 \mathrm{~h}\end{array}$ & $\begin{array}{c}\text { high-temperature solution } \\
\text { heat treatment }\end{array}$ & $\begin{array}{c}\text { double holding time } \\
\text { of solution heat } \\
\text { treatment }\end{array}$ & $\begin{array}{c}\text { 5 repeats of the } \\
\text { solution heat } \\
\text { treatment cycle }\end{array}$ & $\begin{array}{c}\text { extended final } \\
\text { step of solution } \\
\text { heat treatment } \\
\text { to 60-hour } \\
\text { holding }\end{array}$ \\
\hline
\end{tabular}

Aging (applied after all solution treatments)

two-step aging with different temperature holds

images show that tertiary $\gamma^{\prime}$ precipitates were present within the $\gamma$ channels, with a size of $\sim 50 \mathrm{~nm}$ in $\mathrm{S} 2$ and $\mathrm{S} 4(1)$. Both very large $(>100 \mathrm{~nm})$ and fine $(<20 \mathrm{~nm})$ tertiary $\gamma^{\prime}$ precipitates were found in S2 with no tertiary $\gamma^{\prime}$ observed in S1 or S3(1).

The microstructure was further examined using image analysis to quantify the area fraction of the secondary $\gamma^{\prime}$, $\gamma$ channel widths, and the degree of $\gamma^{\prime}$ rafting, the results of which are shown in Figure 4. In single-crystal Ni-based superalloys, the high level of rupture strength and creep resistance results from the high volume fraction of $\gamma^{\prime}$ within the alloy. ${ }^{[10]}$ In this study, the area fraction of $\gamma^{\prime}$ has been used as an indicator of the overall $\gamma^{\prime}$ content of the alloy. Due to the etchant attacking the $\gamma$ phase, a slight overestimation of the area fraction of $\gamma^{\prime}$ may be present as a systematic error within the results. According to the area fraction measurements, the pre-service (S1) and rejuvenated $(\mathrm{S} 3(1))$ samples had a higher area fraction of secondary $\gamma^{\prime}$ when compared to the rafted samples (S2 and $\mathrm{S} 4(1)$ ), which indicates that a better mechanical performance may be expected than the degraded samples.

Although the rafted sample (S2) had the lowest area fraction of secondary $\gamma^{\prime}$ particles of 0.68 , it should be noted that there were also a large number of tertiary $\gamma^{\prime}$ precipitates in the channels, the size of which was relatively large (100 to $200 \mathrm{~nm})$. The presence of these large tertiary $\gamma^{\prime}$ precipitates in the channels will affect the movement of dislocations, which may increase the strength but reduce the ductility of these samples. ${ }^{[19,20]}$ This is supported by the results from TEM examination of short-term creep test samples (Figure 5), where dislocations were observed to be present mainly within the $\gamma$ channels, especially near the edge of the secondary $\gamma^{\prime}$ particles. The impenetrability of the secondary $\gamma^{\prime}$ particles causes the dislocations to move through the $\gamma$ matrix by forced Orowan bowing where the tertiary $\gamma^{\prime}$ precipitates act as pinning points for dislocations. This 


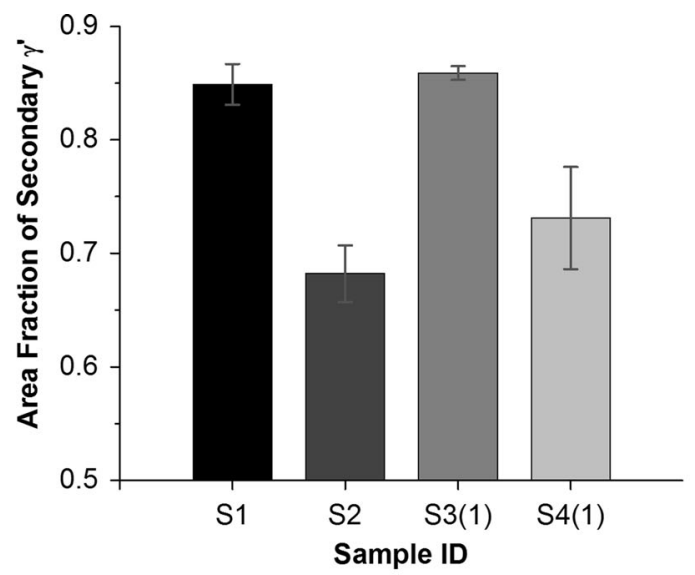

(a)

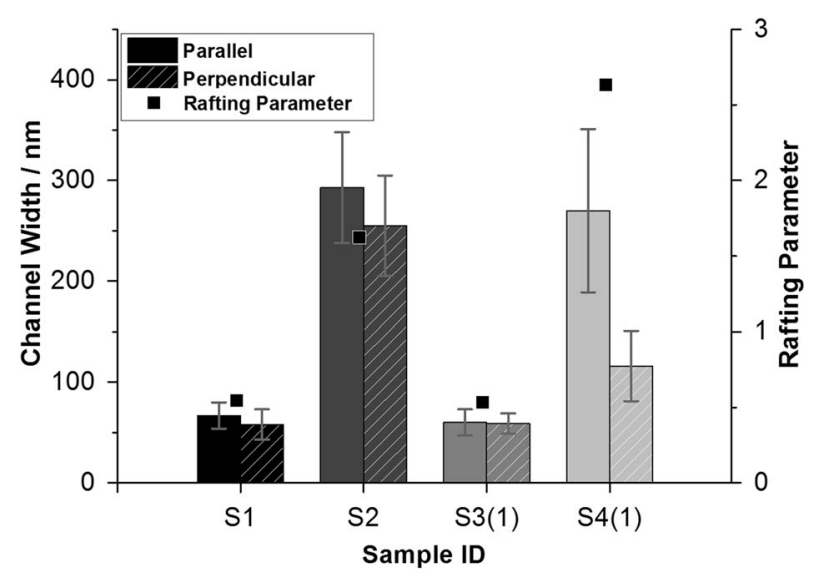

(b)

Fig. 4-Microstructural analysis results of four differently heat-treated samples: $(a)$ area fractions of the secondary $\gamma^{\prime}$ particles, $(b) \gamma$ channel width parallel and perpendicular to the rafting direction and rafting parameter (see Eq. [1]).
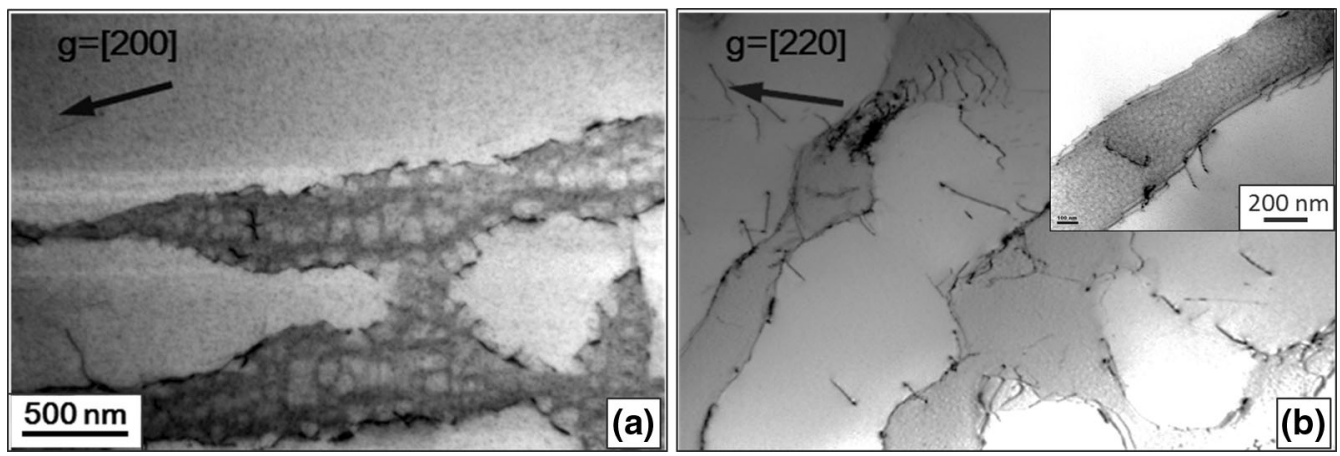

Fig. 5-TEM images of the gauge length of (a) S2, rafted, and (b) S4(1), rafted + R1 + rafted, samples after short-term creep testing at $425 \mathrm{MPa}$ and $1173 \mathrm{~K}\left(900^{\circ} \mathrm{C}\right)$ showing the presence of dislocations in the gamma channels.

process is believed to be beneficial in strengthening of the materials by work hardening. ${ }^{[20,21]}$

In order to quantify the influence of the $\gamma$ channel widths on mechanical properties, these were measured in both the perpendicular and parallel directions with respect to the $\langle 001\rangle$ orientation (Figure 4). The $\gamma$ channel widths in the pre-service (S1) and rejuvenation 1 (S3(1)) samples were very small, $\sim 60 \mathrm{~nm}$, while those in the degraded structures (S2 and S4(1)) were much larger, $\sim 300 \mathrm{~nm}$. The movement of dislocations is governed by the width of these $\gamma$ channels. ${ }^{[22,25,26]}$ When the width is small, a dislocation has to move through the $\gamma^{\prime}$ particles by shearing or cutting, which requires much more energy than to glide through $\gamma \cdot{ }^{[25]}$ When the spacing is larger, as in a rafted structure, dislocations can move by glide through the $\gamma$ channels, which is a process requiring lower stress and thus results in poorer mechanical performance. ${ }^{[25,26]}$

Although the average parallel $\gamma$ channel widths of S2 $(280 \mathrm{~nm})$ and $\mathrm{S} 4(1)(242 \mathrm{~nm})$ showed no significant difference, the channel widths in the perpendicular direction were substantially different. The $\gamma$ channels in S2 had an average width of $250 \mathrm{~nm}$ in the perpendicular direction, while S4(1) measured only $99 \mathrm{~nm}$. The

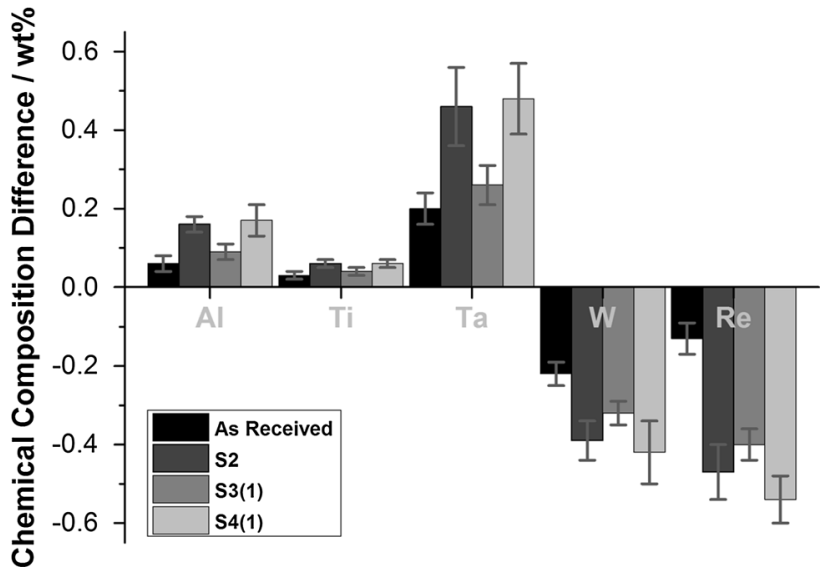

Fig. 6- Chemical composition differences between the dendrite core and interdendritic regions for differently heat-treated samples of CMSX-4.

difference in channel width indicates that the degree of rafting is different between these samples.

As shown in Figure 4(b), the rafting parameter $(R)$ of $\mathrm{S} 1$ and $\mathrm{S} 3(1)$ was very small, $\sim 0.5$, indicating the 

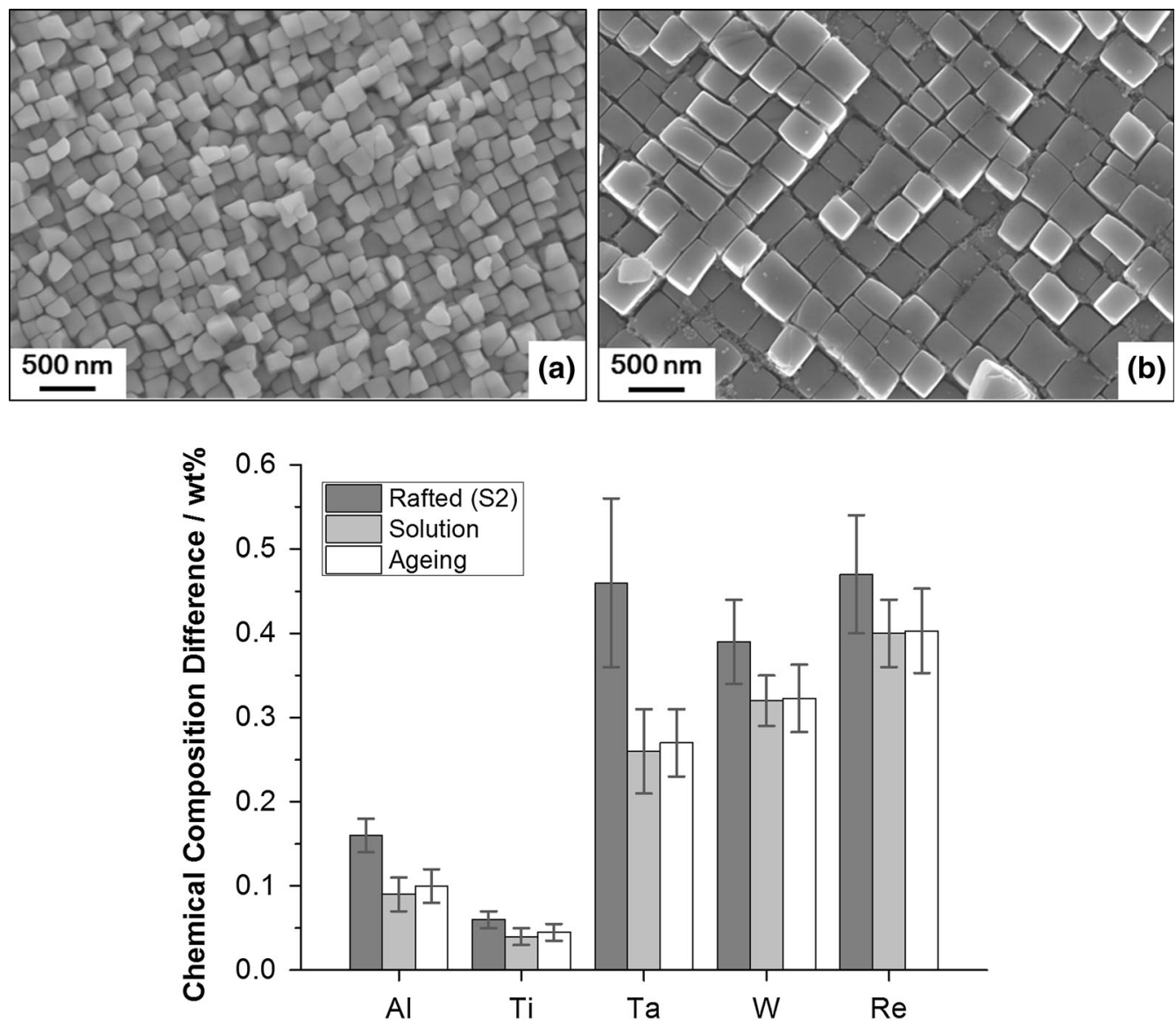

(c)

Fig. 7- SEM images showing the microstructure during rejuvenation (R1) (a) after the solution heat treatment and (b) after aging, and (c) the associated chemical segregation of selected elements within the samples (Note: no dendrite structure was visible, so the data are based on chemical homogeneity).

presence of nearly cubic $\gamma^{\prime}$ particles. The $R$ value for S4(1) (2.65) is much larger than that for S2 (1.64), confirming the observation that $\mathrm{S} 4(1)$ has a more continuous rafted microstructure. The microstructure of the rejuvenation 1 sample $(\mathrm{S} 3(1))$ showed a very similar $\gamma^{\prime}$ size, morphology, and distribution to the pre-service sample (S1), as well as the same degree of rafting. The similarities between these microstructures indicate that the rejuvenation procedure for S3(1) used here restores the microstructure of a rafted sample to a microstructure which is apparently equivalent to that of the pre-service structure. However, when the rejuvenation 1 (S3(1)) sample experienced a subsequent further rafting treatment $(\mathrm{S} 4(1))$, the microstructure showed a greater extent of rafting than the sample which had received only one rafting treatment $(\mathrm{S} 2)$.

\section{B. Chemical Analysis of Dendrite Cores and Interdendritic Regions}

The degradation process experienced during the rafting heat treatment not only degrades the microstructure but can also enhances chemical segregation. Since directional coarsening of $\gamma^{\prime}$ is a diffusive process, it can be very dependent on of the distribution of elements within the alloy. ${ }^{[16,17]}$ Therefore, chemical segregation may affect the mechanical performance of the material by affecting the rafting behavior during high-temperature exposure. As previously shown, the R1 heat treatment appeared to restore the microstructure to the pre-service condition, but, in addition to the microstructure, it is also important to examine the chemical segregation within the alloy after degradation and rejuvenation. In this study, the chemical segregation has been carefully measured with respect to the dendrite structure. The chemical composition difference results are shown in Figure 6, where this is defined as the difference in elemental composition between the interdendritic region (IDR) and the dendritic core (DC).

Most of the elements showed clear chemical differences but the chemical differences in $\mathrm{Al}, \mathrm{Ti}, \mathrm{Ta}, \mathrm{W}$, and Re have been chosen to describe the chemical inhomogeneity in this study. It has been found that $\mathrm{Al}, \mathrm{Ti}$, and Ta were rich in the IDR, but consistently lower in the DC, while Re and W exhibited contrary trends, which is in good agreement with Karunaratne et al. ${ }^{[20]}$ Figure 6 clearly shows that the chemical inhomogeneity in the pre-service sample (S1) was the smallest but increased during a rafting treatment. Although R1 recovered some 

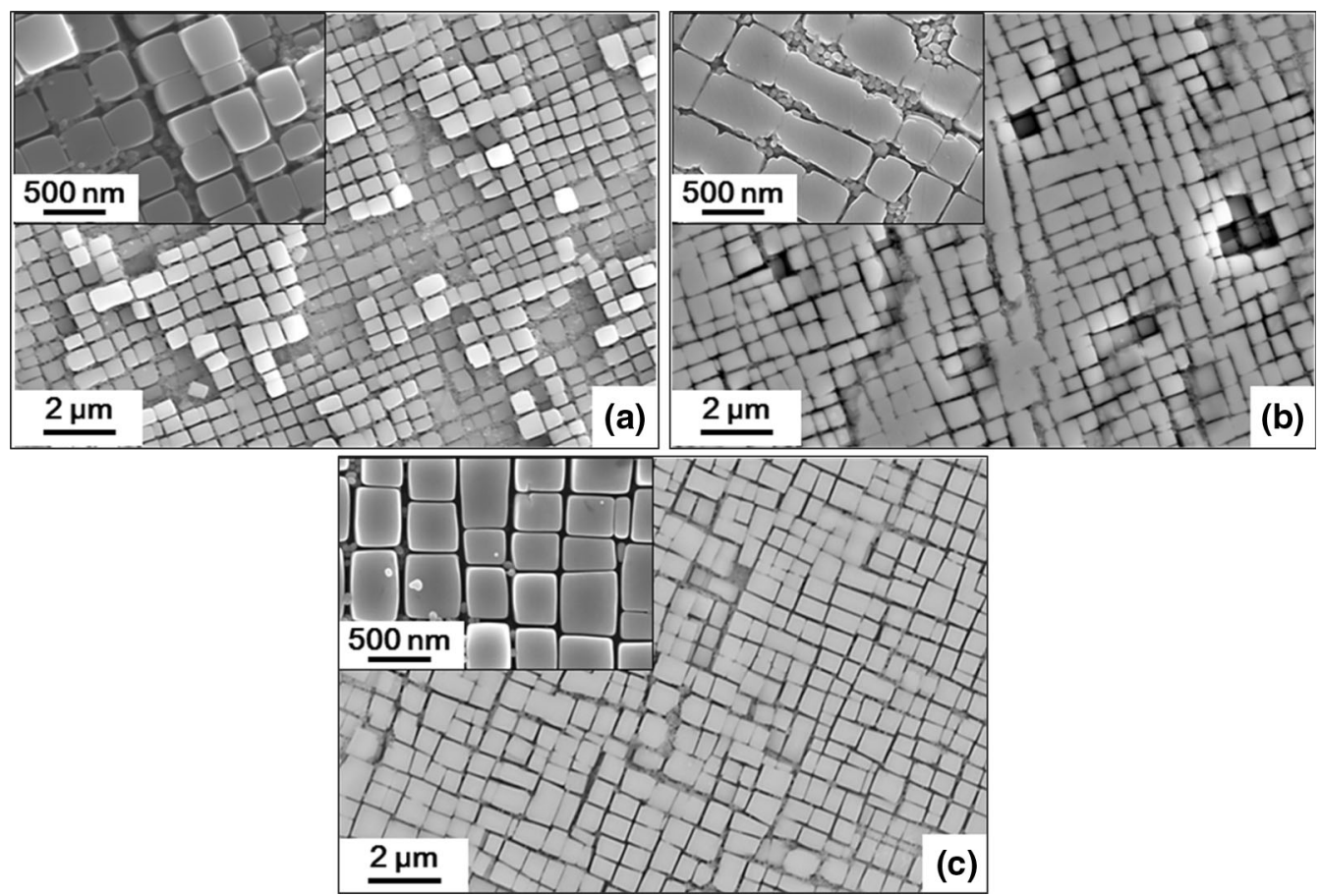

Fig. 8- SEM images of the CMSX-4 samples after three different heat treatments: (a) R2, (b) R3, and (c) R4.

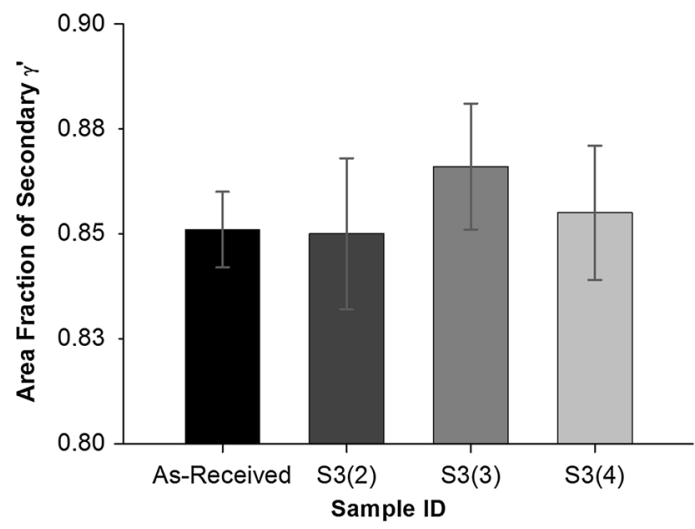

(a)

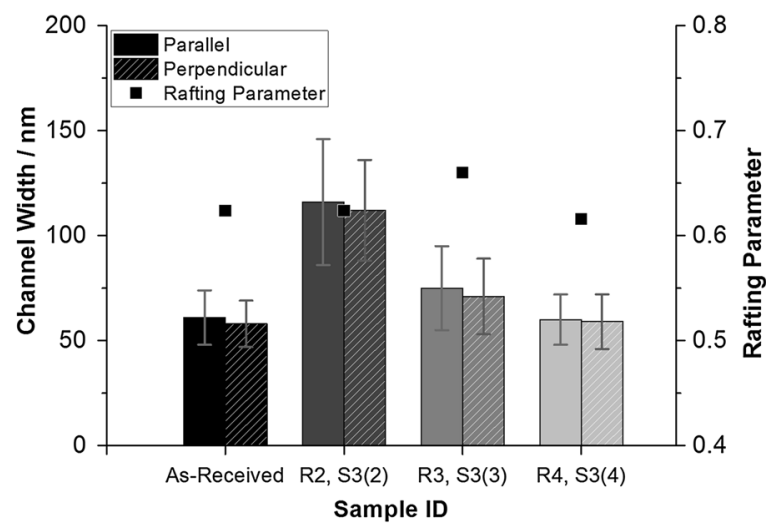

(b)

Fig. 9-Microstructural analysis results of modified rejuvenation trials: $(a)$ area fraction of secondary $\gamma^{\prime}$ particles, $(b) \gamma$ channel width in parallel and perpendicular directions, and rafting parameters.

of this, e.g., $\mathrm{Ti}$ and $\mathrm{Ta}$, it did not recover to the pre-service condition, with $\mathrm{Re}$ and $\mathrm{W}$ remaining very close to the levels observed after rafting. This residual chemical difference is due to the slower diffusion rate of elements such as Re and W. According to Karunaratne et al., ${ }^{[20]}$ the diffusion coefficients of $\mathrm{Re}$ and $\mathrm{W}$ at the rejuvenation heat treatment temperature of $1553 \mathrm{~K}$ to $1593 \mathrm{~K}\left(1280{ }^{\circ} \mathrm{C}\right.$ to $\left.1320{ }^{\circ} \mathrm{C}\right)$ are the lowest of the elements studied, which means that any chemical segregation of these elements is very difficult to eliminate with short-term rejuvenation heat treatments. When S3(1) experienced a further degradation treatment (S4(1)), the residual chemical differences increased even further, as the segregation of slowly diffusing elements, such as $\mathrm{Re}$ and $\mathrm{W}$, is not fully removed during the relatively short-term heat treatment.

\section{Modified Rejuvenation Heat Treatments}

The microstructure and chemical analyses from previous sections suggest that although the $\mathrm{R} 1$ treatment can restore a rafted microstructure back to the pre-service condition, the chemical segregation within the rafted sample may not be completely eliminated. The residual chemical segregation was more pronounced after a second rafting heat treatment, which may cause a subsequent reduction in mechanical performance. Since the segregation of elements with a slow diffusion rate, 


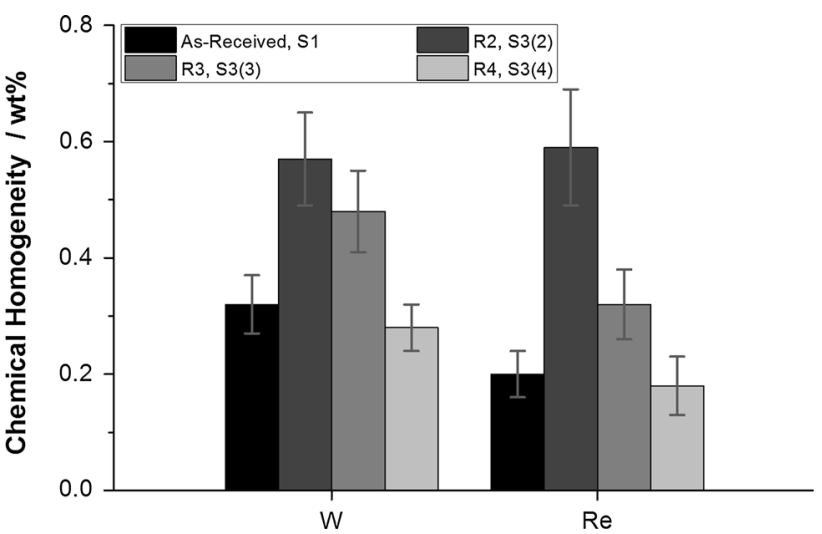

Fig. 10 - Chemical homogeneity of the as-received and three different rejuvenation heat treatment trials based on EDS area analyses (Note: no dendrite structure was visible, so data are based on chemical homogeneity).

Table IV. Creep Test Results of Different Heat-Treated Samples [1255 K $\left(982{ }^{\circ} \mathrm{C}\right)$ and $\left.167 \mathrm{MPa}\right]$

\begin{tabular}{llc}
\hline Sample No & Heat Treatments & Creep Life (h) \\
\hline S1 & pre-service & 1187 \\
S2 & rafted & 807 \\
S3(1) & rafted + R1 & 1291 \\
S4(1) & rafted + R1 + rafted & 804 \\
S3(4) & rafted + R4 & 1174 \\
S4(4) & rafted + R4 + rafted & 780 \\
\hline
\end{tabular}

such as Re and $\mathrm{W}$, is not easily eliminated by short-term rejuvenation, the heat treatment was modified by extending the length of the holding time. In order to design a modified heat treatment, it is important to understand the effect of each stage of the heating process. In order to achieve this, the samples were examined after the solution heat treatment stage and after the aging stage of heat treatment. Although the aging step is necessary to generate an ideal $\gamma^{\prime}$ structure within the alloy (Figures 7(a) and (b)), the solution heat treatment plays a more important role in the elimination of chemical segregation (Figure 7(c)). Therefore, it was decided that the modified rejuvenation heat treatments would focus on the extension of the solution heat treatment, while keeping the aging stage constant throughout. Details of the heat treatments applied are shown in Table III.

Figure 8 shows the microstructures of the samples after the modified rejuvenation heat treatments, with the area fraction of secondary $\gamma^{\prime}$ particles, $\gamma$ channel width, and rafting parameters shown in Figure 9. The size and distribution of cuboidal $\gamma^{\prime}$ in all of the rejuvenated samples is equivalent to that in the pre-service (S1) and rejuvenation $1(\mathrm{~S} 3(1))$ samples. Very fine tertiary $\gamma^{\prime}$ measuring $\sim 30 \mathrm{~nm}$ was also found in all samples. However, some differences between these samples have been found. The $\gamma$ channel width obtained after R2 $(115 \mathrm{~nm})$ is greater than that after R1 $(60 \mathrm{~nm})$ in both the parallel and perpendicular directions.

This microstructure indicates that $\mathrm{R} 2$ failed to recover the microstructure to the pre-service condition, but instead increased the $\gamma$ channel width which would be likely to result in a deterioration of mechanical properties. ${ }^{[19,23,27]}$ The sample that underwent R3 had a larger degree of rafting with a rafting parameter of 0.65 . This is confirmed by the observation of some rafts in Figure $8(b)$. This increased tendency to form rafts may be detrimental to the mechanical properties as it provides less of a barrier to dislocation motion. ${ }^{[23,27]} \mathrm{R} 4$ developed a well-recovered microstructure with no evidence of detrimental effects.

The purpose of extending the rejuvenation heat treatment was to reduce chemical segregation, and therefore this was also examined. Since the chemical segregation of $\mathrm{W}$ and $\mathrm{Re}$ is the most pronounced, these two elements were used in this comparison. Figure 10 shows the chemical differences in the rejuvenated and the pre-service samples. The chemical differences are smallest in the pre-service sample. As previously discussed, although R1 has reduced some of the inhomogeneity, there still exists a large degree of segregation within the alloy. For extended rejuvenation trials, the inhomogeneity has been successfully reduced. For R4, the chemical segregation level was very close to the pre-service condition. The results suggest that extending the rejuvenation heat treatment is beneficial for eliminating the chemical segregation and $\mathrm{R} 4$ appears to contain similar chemical segregation to the pre-service condition, which may be beneficial to the long-term mechanical performance of this material.

\section{Mechanical Tests}

Creep tests were carried out on samples before and after different rejuvenation heat treatments (R1 and R4) to compare and evaluate their performance. R4 is the most promising rejuvenation heat treatment based on the observed microstructure and chemical segregation recovery achieved. Table IV illustrates the results of the creep rupture tests for different heat-treated samples at $1255 \mathrm{~K}\left(982{ }^{\circ} \mathrm{C}\right)$ and a stress of $167 \mathrm{MPa}$.

The pre-service (S1) sample has a creep rupture life of 1178 hours, which is in good agreement with the expected life of the test sample. ${ }^{[21]}$ The creep rupture life of S2 (rafted) is significantly reduced compared to S1 (pre-service) (807 hours). The high-temperature rejuvenation (R1) sample, S3(1), and the extended rejuvenation (R4) sample, S3(4), show creep rupture lives similar to those for the pre-service material. In order to evaluate the performance of the different rejuvenation processes, rejuvenated samples were creep tested after a subsequent rafting heat treatment. The creep rupture lives of these samples were very similar: 804 hours for S4(1) and 780 hours for S4(4), which is consistent with the rafted pre-service sample (S2). The results indicate that, in addition to successful chemical segregation reduction, the extended rejuvenation heat treatment (R4) has a similar effect on the mechanical performance of the alloy to R1, in that it restored the creep life to the pre-service condition. However, the results shown here are relatively short-term tests, so the effect of the reduction in chemical segregation on the long-term mechanical behavior of the rejuvenated alloy is as yet unknown and will form the basis of future research in this area. 


\section{CONCLUSIONS}

The microstructural evolution and mechanical behavior of differently degraded and rejuvenated CMSX-4 samples have been examined; a number of conclusions can be drawn as follows:

1. Although the microstructures of the rejuvenation 1 (S3(1)) and pre-service (S1) samples have very similar $\gamma^{\prime}$ area fractions, channel widths, and rafting parameters, their microstructural evolution during high-temperature degradation resulted in large differences in $\gamma$ channel width and $\gamma^{\prime}$ rafting parameter.

2. Chemical segregation is one of the likely explanations for the differences observed after a second rafting heat treatment, because chemical segregation is not removed during rejuvenation and, in addition, is enhanced by a second degradation process.

3. An extended rejuvenation heat treatment (R4) was found to significantly reduce the extent of chemical segregation within the alloy, with the same distribution and size of the secondary $\gamma^{\prime}$ and the tertiary $\gamma^{\prime}$ precipitates inside channels as the pre-service condition.

4. Under the creep test conditions used in this research, the reduced chemical segregation present after a longer rejuvenation heat treatment does not seem to influence the short-term creep life of the material or the extent of degradation after a subsequent rafting treatment. The effect of this reduced extent of chemical segregation on long-term creep properties will be the subject of future work.

\section{OPEN ACCESS}

This article is distributed under the terms of the Creative Commons Attribution 4.0 International License (http://creativecommons.org/licenses/by/4.0/), which permits unrestricted use, distribution, and reproduction in any medium, provided you give appropriate credit to the original author(s) and the source, provide a link to the Creative Commons license, and indicate if changes were made.

\section{REFERENCES}

1. R.C. Reed: The Superalloys: Fundamentals and Applications, Cambridge University Press, London, 2006.

2. T.M. Pollock, N. Rene, and S. Tin: J. Propul. Power, 2006, vol. 22 (2), pp. 361-74.

3. M. Nazmy, A. Epishin, T. Link, and M. Staubli: Energy Mater., 2006, vol. 1 (4), pp. 263-68.

4. E. Lvova and D. Norsworthy: J. Mater. Eng. Perform., 2001, vol. 10, pp. 299-12.

5. A. Epishin, T. Link, U. Brückner, B. Fedelich, and P. Portella: Superalloys, 2004, pp. 537-43.

6. C.M.F. Rae and R.C. Reed: Acta Mater., 2001, vol. 49 (19), pp. 4113-25.

7. A. Epishin, T. Link, M. Nazmy, M. Staubli, and G. Nolze: in Proceedings of Superalloys 2008, R. C. Reed et al., eds. 2008, pp. 725-731.

8. A. James: Mater. Sci. Technol., 2001, vol. 17 (5), pp. 481-86.

9. A. Baldan: J. Mater. Sci., 1991, vol. 26 (13), pp. 3409-21.

10. R.C. Reed, D.C. Cox, and C.M.F. Rae: Mater. Sci. Technol., 2007, vol. 23 (8), pp. 893-902.

11. M. Kamaraj, K. Serin, M. Kolbe, and G. Eggeler: Mater. Sci. Eng. A, 2001, vol. 319, pp. 796-99.

12. R.A. MacKay and M.V. Nathal: Acta Metall. Mater., 1990, vol. 38 (6), pp. 993-1005.

13. M.V. Nathal and L.J. Ebert: Scripta Metall., 1983, vol. 17, pp. 1151-54.

14. T. Murakumo, Y. Koizumi, K. kobayashi and H. Harada: Superalloys 2004, K. A. Green, T. M. Pollock, H. Harada, T. E. howson, R. C. reed, J. J. Scirra and S. Walston, eds., pp. 115-62.

15. R.A. MacKay and L.J. Ebert: Met, Trans. A, 1985, vol. 16, pp. 1969-82.

16. K.Y. Cheng, C.Y. Jo, D.H. Kim, T. Jin, and Z.Q. Hu: Mater. Charact., 2009, vol. 60 (3), pp. 210-18.

17. T. Niki, K. Ogawa, and T. Shoji: Key Eng. Mater., 2007, vols. 353-358, pp. 537-40.

18. C.T. Sims, N.S. Stoloff, and W.C. Hagel: Superalloys II, Wiley, New York, 1987.

19. G.E. Fuchs: Mater. Sci. Eng. A, 2001, vol. 300 (1-2), pp. 5260.

20. M.S.A. Karunaratne, C.M.F. Rae, and R.C. Reed: Metall. Mater. Trans. A, 2001, vol. 32A (10), pp. 2409-21.

21. J. Svoboda and P. Lukas: Acta Mater., 1998, vol. 10, pp. 3421-31.

22. Z. Yao, C.C. Degnan, M.A.E. Jepson, and R.C. Thomson: Mater. Sci. Technol., 2013, vol. 29 (7), pp. 775-80.

23. M. Ignat, J.-Y. Buffiere, and J.M. Chaix: Acta Metall. Mater., 1993, vol. 41 (3), pp. 855-62.

24. ASTM: E139 standard test methods for conducting creep, creep-rupture, and stress-rupture tests of metallic materials 1. Annu. B. ASTM Stand. 4, pp. 1-14, 2014.

25. T.M. Pollock and A.S. Argon: Acta Metall. Mater., 1992, vol. 40 (1), pp. 1-30.

26. R. Jensen and J. Tien: Metall. Trans. A, 1985, vol. 16 (6), pp. 1049-68.

27. M. Durand-Charre: The microstructure of superalloys, CRC Press, Paris, 1998. 